\title{
Analysis on the PM2.5 Concentration During Heating and Cooking in Cold Rural Areas of Northern China
}

\author{
Xueyan Zhang ${ }^{*}$, Bin Chen \\ Laboratory of Building Environment and New Energy Resources, Dalian University of Technology, \\ Dalian, Liaoning 116024, China \\ *zxychenggong2008@126.com
}

\begin{abstract}
Keywords: Rural houses; PM2.5 emissions; Heating systems; Air quality
Abstract. In Northern China, most traditional heating systems, heated by mini-stove in the kitchen, usually take agricultural residues as fuels resources. Besides, burning cave under the ground-floor of a rural house is also widely used. Exhausted flue gases from these heating systems contain many harmful components and particulate matters discharge into atmosphere and usually seep into the room, which is crisis for human health. In this paper, the emission process of inhalable particles has been measured during the heating and cooking period in three rural households in Fuxin city, Liaoning province have been investigated. The measurements were correlated to factors such as living habits, indoor air temperature, indoor relative humidity, biomass fuels, and ventilation methods. The indoor PM2.5 concentration of a rural house is 2 to 4 times more than the secondary limits of $75 \mu \mathrm{g} / \mathrm{m}^{3}$ in Chinese standard. The upper and lower ratio of PM2.5 concentration between kitchen and bedroom respectively are 0.75 and 1.63. In addition, the impact of outdoor wind speed and predominant wind direction on the PM2.5 emission has been studied.
\end{abstract}

\section{Introduction}

About 3 billion people in developing countries using solid fuels combustion for cooking food and heating rooms such as dung, wood, and agricultural residues [1]. Combustion of these fuels is generally inefficient, producing high levels of particulate matter less than $0.25 \mu \mathrm{m}$ in size (PM 2.5) and $\mathrm{CO}$ [2]. Their toxic effects have been extensively documented [3]. Although many investigations in China have examined the impact of air pollution, these studies have largely been confined to major urban areas, Missing are data for rural areas where combustion of agricultural residue in caves is the major source of heating. Particularly concern of PM 2.5 levels discharged into outdoor atmosphere and flow into the house. This study could fill the pollution research gap.

\section{Measured houses and conditions}

In this study, pollution concentrations of the three typical rural houses in northern china heated by traditional heating systems have been measured. In addition, indoor and outdoor PM2.5, PM10 concentration and CO concentration have been measured and analyzed. These three houses were located in Hapeng location, Fuxin city, Liaoning Province, shown in Table 1. The study period was from Dec.6, 2013 to Dec.7, 2013.

According to the testing requirements in "Ambient Air Quality Standard"(DEP 2012), SHINYEI PM2.5 Sensor assessment monitors have been used for recording with 10 minutes interval, which have highly testing accuracy about $85 \%$, and broader measurement range from $0 \mu \mathrm{g} / \mathrm{m}^{3}$ to 200 $\mu \mathrm{g} / \mathrm{m}^{3}$. The CO concentration has been recorded by indoor air quality-TSI7545. The indoor and outdoor temperature and relative humidity have been measured by thermo recorder TR-72U. Before recording, the doors and windows of the room have been closed for more than 24 hours. If the area of one heating room was less than $50 \mathrm{~m}^{2}$, the testing point could only be one, and the height of the testing point could be $1.2 \mathrm{~m}$. 
Table1. Basic information of measured rural houses in Fuxin rural areas (Hapeng location)

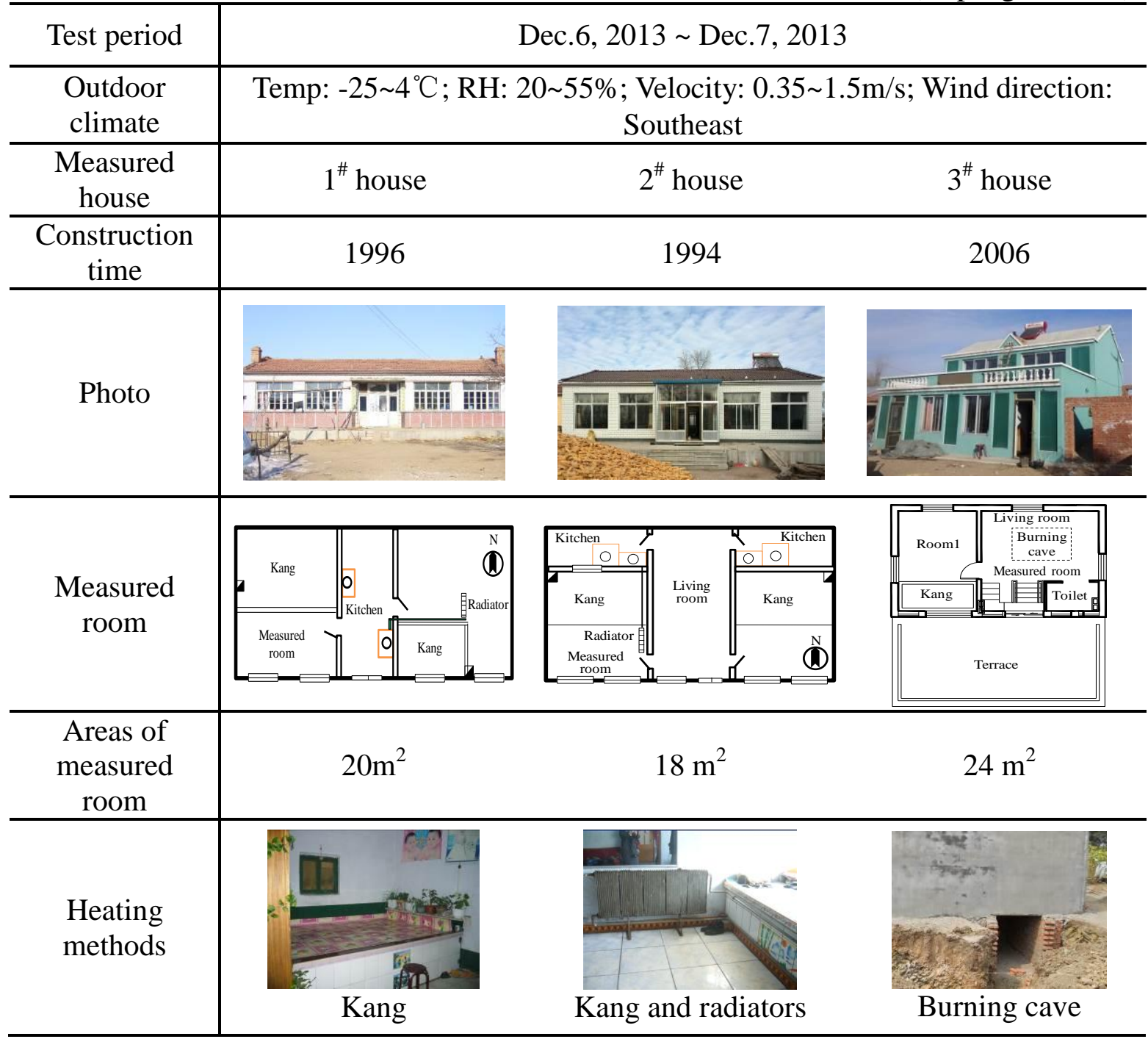

\section{Results and discussion}

Factors influencing on the PM2.5 concentration. From Fig.1, the concentration of PM2.5 inside and outside rural houses were 2 to 4 times exceeding the secondary limits in Chinese national standards [4], at about $80 \%$ of the total time was exceeding obviously. Since the fuels smoldering, if the sealed property of the heating system is poor, $\mathrm{CO}$ and other harmful gases could infiltrate in the heating room. And the indoor and outdoor concentrations of harmful gases could be increased significantly. The higher levels generally occurred at the cooking time on the morning at 06:30 and in the afternoon at 18:00. However, the decline stage of PM2.5 concentration was from 1:00 to 6:00 during the sleeping stage. The significant differences among these results were mainly occurred due to biomass types and different burning approaches for heating and cooking both hourly and over longer periods during the 24-hour test.

The main influencing factors on the PM2.5 concentration are summarized as follows: (1) Indoor heating systems in different rural residents are intermittent mode combined with cooking and heating, resulting in a cyclical variation of PM2.5 concentrations; (2) The impact of indoor thermal environment, relative humidity on PM2.5 diffusion could be carried out; (3) Various fuel types and combustion process in different energy applications bring out different PM2.5 concentrations; (4) Residential space layout influencing on the air flow rate and emission process, resulting in a interrelated variation of PM2.5 concentration between adjacent rooms; (5) Under the condition of ventilation through windows, PM2.5concentration of the heating room was greatly influenced by cold air flow rate, air flow path and outdoor PM2.5 concentration. 


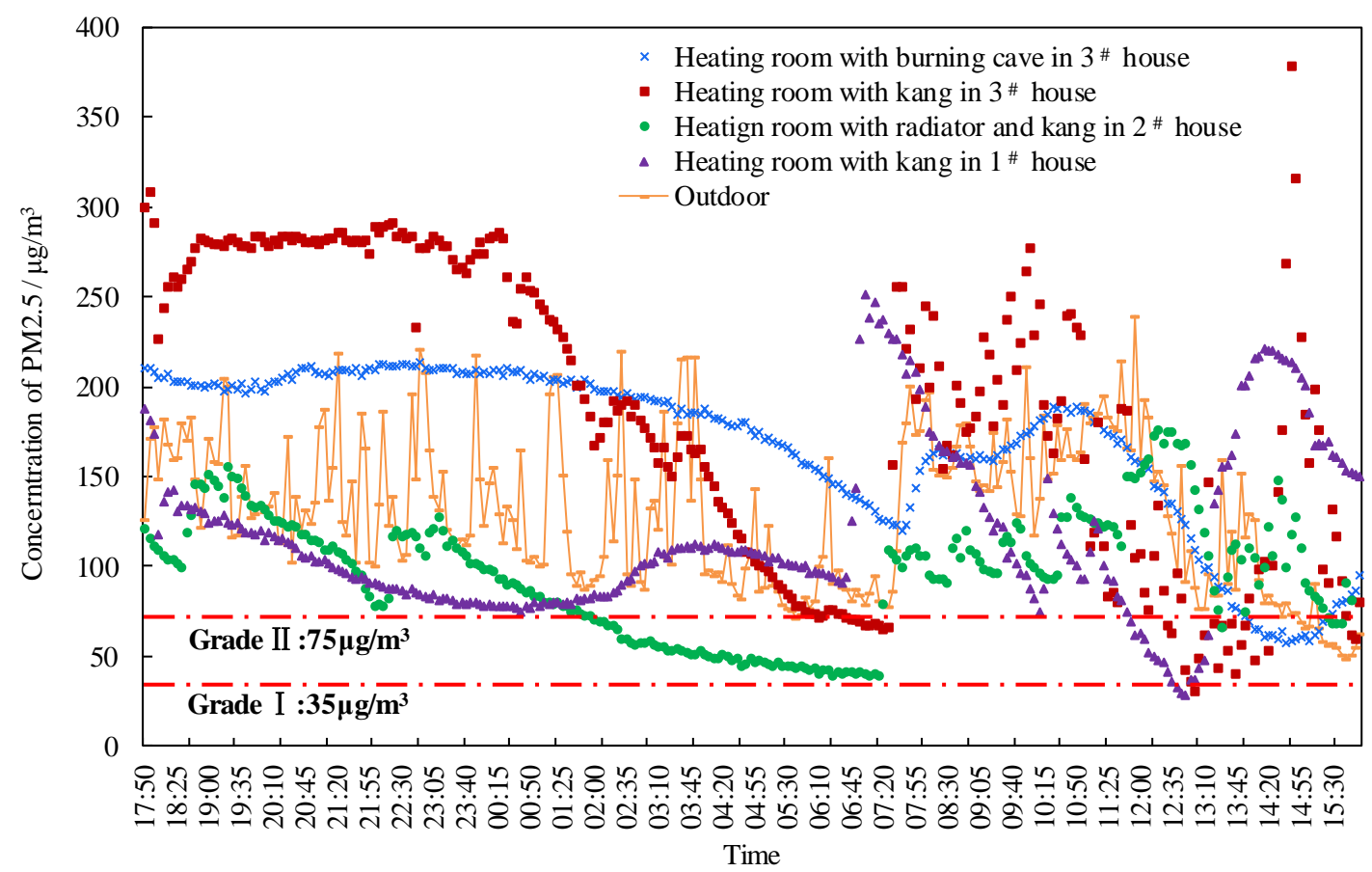

Fig. 1. Variations of PM2.5 concentrations（DEC.6 DEC.7. 2013）

Ventilation modes impact on PM2.5 concentration. During the cooking period about one hour, the mixture of straws and woods were used as fuels, whose combustion mode was full burning, and the combustion efficiency was $100 \%$. From the Fig.2, the variation range of the positive correlation coefficient was from 0.75 to 1.63 between the PM2.5concentration of a kitchen and which in a bedroom. While ventilation was taken out during cooking period through the door, the variation range of the positive correlation coefficient was from 0.81 to 1.87 .

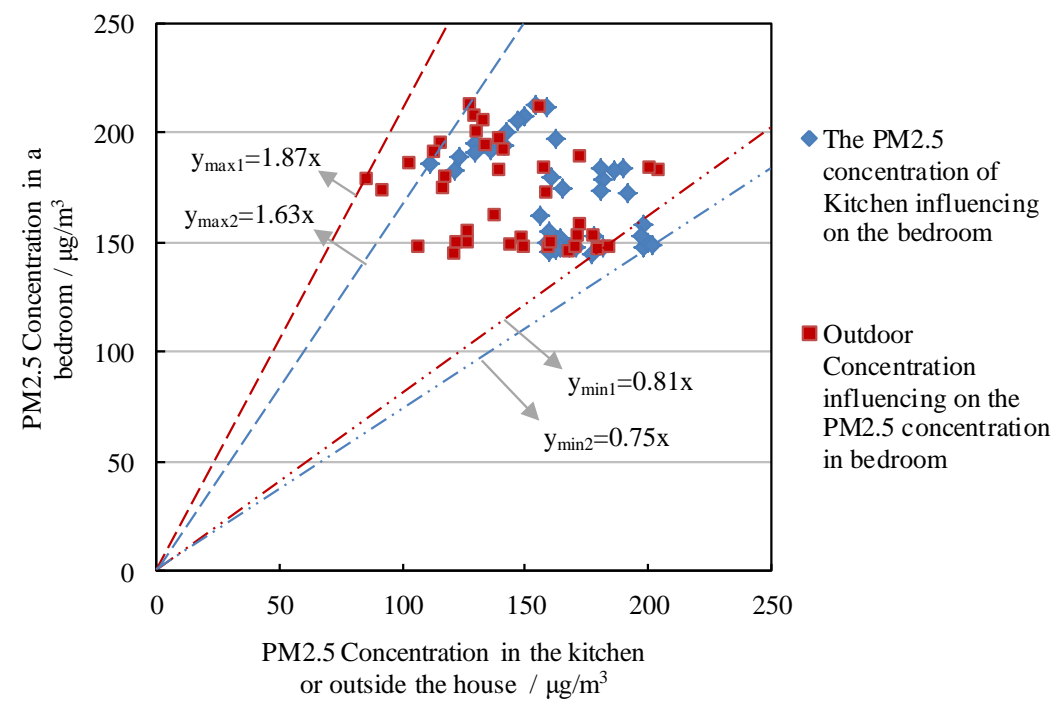

Fig.2 The concentration of PM2.5 in kitchen influencing on which in bedroom ( $2^{\#}$ house in Fig. 1, during the cooking period)

Variation of outdoor PM2.5 concentration. As shown in Fig. 3, the PM2.5 concentration is up to $2.72-3.15 \mathrm{mg} / \mathrm{m}^{3}$, while the temperature of exhaust gas was $59.3^{\circ} \mathrm{C}$, and the heat flux of the heating system was $0.45 \mathrm{~L} / \mathrm{min}$. The wind velocity is from $0.5 \mathrm{~m} / \mathrm{s}$ to $1.5 \mathrm{~m} / \mathrm{s}$, and typical chimney diameter is $100 \mathrm{~mm}$, the amount of flue gas in heating and cooking is approximately from 14 to 42 $\mathrm{m}^{3} /$ (h.household). PM2.5 emission is from 1.536 million households of Fuxin. Assuming the PM2.5 concentration is $125 \mu \mathrm{g} / \mathrm{m}^{3}$, with the emission from 13 to $41 \mathrm{~kg} /$ day and assuming the heating period in winter contains 176 days, the total emission of PM2.5 would be between $2.4 \mathrm{t}$ and $7.2 \mathrm{t}$ per house. 

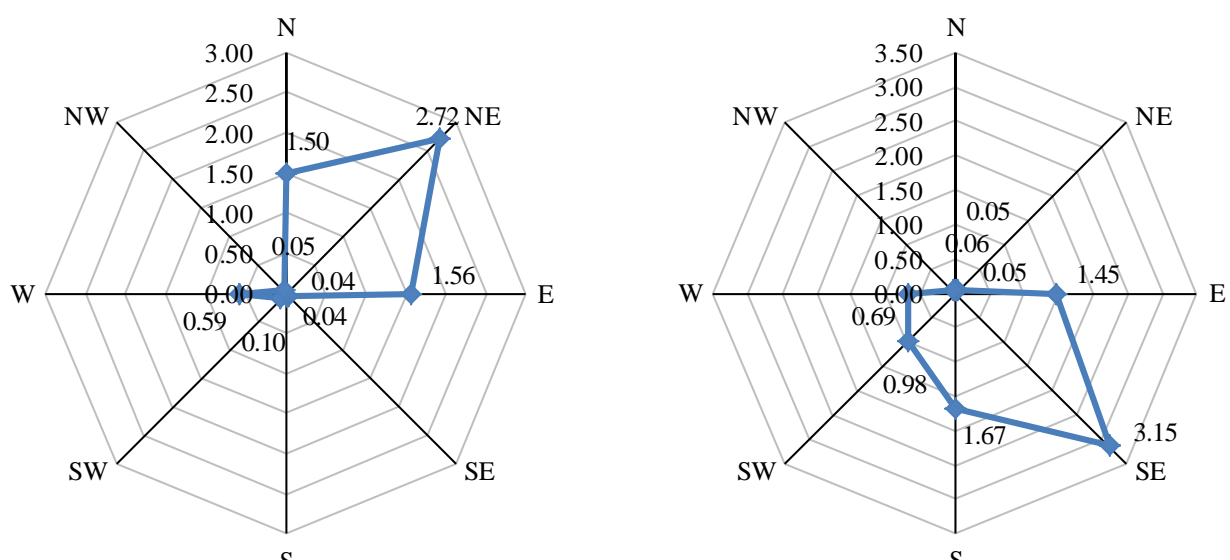

Fig. 3. The impact of predominant wind direction on outdoor PM2.5 concentration (Unit: $\mathrm{mg} / \mathrm{m}^{3}$ )

As shown in Fig. 4, the PM2.5 concentration during the cooking period is highest to $3.15 \mathrm{mg} / \mathrm{m}^{3}$. The correlation coefficient between PM2.5 concentration and wind speed is about 0.23 .

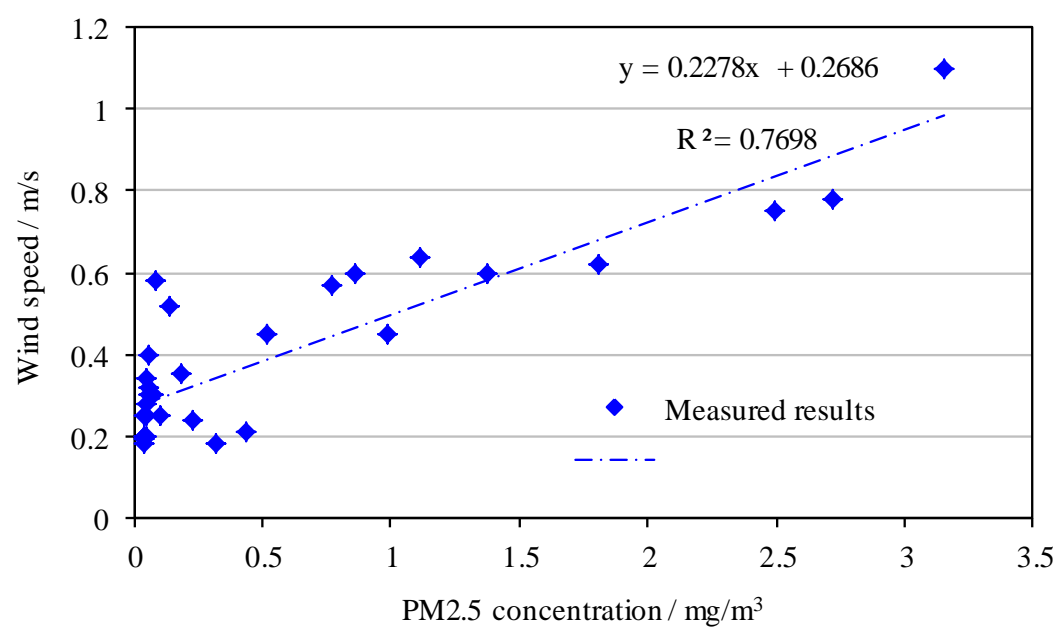

Fig. 4. The impact of wine speed on outdoor PM2.5 concentration

\section{Conclusions}

Some significant conclusions are as follows: (1) The indoor PM2.5 concentration of a rural house is 2 to 4 times more than the secondary limits of $75 \mu \mathrm{g} / \mathrm{m}^{3}$ in Chinese standard. (2) The upper and lower ratio of PM2.5 concentration between kitchen and bedroom respectively are 0.75 and 1.63. (3) PM2.5 pollution from the rural area such as Fuxin city surrounding the urban areas could be between $2.4 \mathrm{t}$ and $7.2 \mathrm{t}$ per house. Besides, this problem could not be overlooked.

\section{Acknowledgements}

The work was supported by a NSFC (No.51178073) and a postdoctoral science foundation (No.2015M571306) of China.

\section{References}

[1] C.L. Li, S.C. Kang, P.F. Chen, et al. (2012). Atmospheric Environment. 59(2012): 207-213.

[2] C. Armendariz-Arnez, R.D. Edwards, M. Johnson, et al. Atmospheric Environment. 44(2010): 2881-2886.

[3] Q. Zhang, D.G. Streets, G.R. Carmichael., et al. Atmospheric Chemistry and Physics. 9(2009): 5131-5153.

[4] Department of environmental protection. Ambient air quality standards (GB3095-2012). First ed., China Environmental Science Press, Beijing, 2012. 